\title{
Active Integration of Patients into Infection Control, as perceived by Health Care Professionals: Results of the AHOI Pilot Study
}

This article was published in the following Dove Press journal: Infection and Drug Resistance

\author{
Stephan Diedrich $\mathbb{1}^{1, *}$ \\ Tillmann Görig (1D ${ }^{2, *}$ \\ Kathleen Dittmann (iD) ${ }^{2}$ \\ Axel Kramer ${ }^{3}$ \\ Claus-Dieter Heidecke' \\ Nils-Olaf Hübner ${ }^{2}$ \\ 'Department of General Surgery, \\ Visceral, Thoracic and Vascular Surgery, \\ Universitätsmedizin Greifswald, \\ Greifswald, Germany; ${ }^{2}$ Central Unit for \\ Infection Prevention and Control, \\ Universitätsmedizin Greifswald, \\ Greifswald, Germany; ${ }^{3}$ Institute of \\ Hygiene and Environmental Medicine, \\ Universitätsmedizin Greifswald, \\ Greifswald, Germany \\ *These authors contributed equally to \\ this work
}

Objective: Medical professionals have a key role in active patient involvement in infection control and prevention (ICP). ICP of hospital-associated infections is critical for patient safety and requires targeted integration of patients and their relatives. The possibilities of proper involvement are identified, tested and realized in the innovative AHOI project. Its acronym stands for Activation, Help, Open communication and Infection prevention. The project is based on the three dimensions acceptance, empowerment and adherence. The results presented here are from a health-care professional (HCP) focused part of a pilot study to implement AHOI intervention. This section aimed at the HCPs' evaluation of the intervention material, their perception and acceptance of the adherence and empowerment of patients, as well as the perception of their and colleagues' own behavior.

Methods: The cross-sectional survey was conducted with a questionnaire at two surgical wards of a third-level hospital for 14 weeks. All HCPs with contact to patients were entitled to voluntarily participate in the study. AHOI instruments such as visual reminder, videos for patients and the AHOI-box were implemented on the wards. Additionally, the ward personnel received a psychological and practical train-the-trainer curriculum.

Results: Sixty-nine questionnaires were handed out and 29 returns were analyzed. The results show a strong identification and acceptance of HCPs with their role in the AHOI project. No additional workload was perceived by implementing AHOI. Teaching of medical professionals and information materials are seen as good supports. HCPs are empowering hygienic behavior in patients and colleagues. HCPs observed increasing adherence of patients.

Conclusion: HCPs positively perceived acceptance, support and identification with the ideas of the AHOI project. Therefore, since HCPs are key for patients and their relatives, AHOI intervention seems to be a feasible instrument and aid in implementing national and international recommendations for hygienic behavior.

Keywords: healthcare professional, patient involvement, patient empowerment, patient adherence, patient safety, infection control

\section{Introduction}

The World Health Organization (WHO) is recommending involving patients in hand hygiene as a key element of infection control and prevention (ICP) since 2009. ${ }^{1}$ This recommendation carries the idea that everyone involved in the medical process have to be included in the active and passive components of the treatment. ${ }^{2-5}$ Promising studies for improvement of infection control and patient safety through better teaching and
AHOI-Projekt, Zentralbereich Hygiene,

Universitätsmedizin Greifswald, WaltherRathenau-Straße 49a, Greifswald I7475,

Germany

Tel $+49(0) 3834515598$

Fax +49 (0)38345I 55 9l

Email tillmann.goerig@med.uni-

greifswald.de
Infection and Drug Resistance 2020:13 4009-4019

4009 
integration of the patient have been published previously. ${ }^{6-19}$ Building on this idea, the new cross-media strategy "AHOI patient on board" is set to go one step further by involving both patients and their relatives, not only in hand hygiene, but also in an active role in ICP. AHOI stands for Activation, Help, Open communication and Infection prevention and is based on three dimensions:

- Adherence - patients and visitors know hygiene standards and realize them,

- Empowerment - patients and visitors should consciously observe the hygienic behavior of the personnel and should be able to address noticeable abnormalities, and

- Acceptance - health-care professionals (HCPs) should convey the feeling to patients and visitors that they are on equal footing in terms of ICP and patient safety. ${ }^{20-22}$

AHOI was implemented as a pilot study to evaluate the feasibility approach for a large comparative intervention study. An important aspect of implementing an innovative prevention attempt is the cooperation of HCPs. ${ }^{4}$ As HCPs are in direct contact with patients and relatives, they are the closest available partners during hospitalization and have a key role in involving patients and relatives in ICP. Therefore, AHOI is constructed in such a way that not only patients and their relatives are involved in infection prevention, but also include the HCPs in the cultural change in order to accept and welcome patient involvement. This is a relatively new aspect compared to older approaches. ${ }^{23}$ Still, data on how well HCPs accept an active role of themselves, patients and relatives are scarce and further research is necessary. ${ }^{5,24,25}$ Previous studies show that the desired involvement of patients can lead to ambivalent situations and structures, especially with regard to culture and behavior. ${ }^{26}$

AHOI feasibility study findings from the patients' perspective and other AHOI findings were described previously. ${ }^{27,28}$

The results presented here are from a HCP focused part of that pilot study. The here reported results primarily aimed at the acceptance of the innovative AHOI project by HCPs, the evaluation of the intervention material and the implementation of the AHOI project. Of further interest were the HCPs' perception and acceptance of adherence and empowerment of patients as well as their own behavior and that of colleagues.

\section{Materials and Methods}

\section{Study Design}

AHOI is a cooperation between the Institute of Hygiene and Environmental Medicine, the Department of General Surgery, Visceral, Thoracic and Vascular Surgery of University Medicine Greifswald and the Chair of Business Administration and Health Care of the University of Greifswald. University Medicine Greifswald is a tertiary care hospital with over 900 beds. It is the largest hospital in the district of Greifswald-Western Pomerania. The study was a feasibility study based on a cross-sectional design. The study was approved by the medical ethics commission of University Medicine Greifswald (BB 087/16a) and is reported following the STROBE guidelines. ${ }^{29}$

\section{Participants and Interventions}

The AHOI instruments were implemented at two surgical wards of the surgical department. Study duration was 14 weeks (26th January - 3rd May 2017). Participation was strictly voluntary and pseudonymized for HCPs as well as patients and relatives. All HCPs with contact to patients (including surgeons, nurses, nursing apprentices and ward management assistants) were entitled to participate in the study. Likewise, all patients over 18 years of age were eligible to participate with a patient-oriented questionnaire. Exclusion criteria were an inability to comprehend the AHOI concept, eg, due to lack of German language knowledge.

Interventions included measures for HCPs, patients and the ward environment: At both wards, a multimodal intervention setup with information and motivational material, eg, posters, brochures, video presentations and welcomeboxes for patients, was implemented. The HCPs received a structured psychological curriculum and practical training for six hours in small groups to become acquainted with the AHOI approach and its background: Key aspects were interdisciplinary train-the-trainer teaching, communication tools and skills for empowering patients and following acceptance, as well as role-playing and dealing with criticism. The curriculum was developed, guided, and supervised by psychologists and mental trainers.

A central instrument from the patient's viewpoint was the "AHOI welcome-box" which was distributed to all inpatients upon admission (see Supplement 1A). It included a brochure that included information about infection risks, hygiene rules in general and in medical institutions as well as supporting incentives. Different Posters and visual 
reminders were installed in the entrance hall of the hospital, ward corridors, patient rooms and sanitary facilities (see Supplement 1B). Two animated videos ("Mention It!" and "Stay clean - disinfect your hands!") were presented as continuous loops on screens in the entrance hall and on a separate channel on the patient's bedside TV.

\section{Outcomes and Data Collection}

The primary research questions were the feasibility of implementing the AHOI instruments developed and their acceptance by HCPs. This included the HCPs' evaluation of the AHOI materials and training. Secondary the survey asked for the subjectively perceived behavior, adherence and empowerment of patients, relatives and other HCPs by the respondents.

Data were collected using a questionnaire with 116 items (Supplement 3). Questions were mainly constructed as closed items with nominal, ordinal and semi-interval scales (eg, "yes - no"; 5-point-scale: "totally agree" "disagree"; 10-point-scale: "negative - positive"; or as a 11-point-scale: " $0 \% "$ - " $100 \% ")$. To characterize the participating personnel, several demographic items such as sex, age and occupational group, were recorded. The age of the respondents was recorded on a 6-point-scale $(1=18-25$ years, $2=26-35,3=36-45,4=46-55,5=56-65$, $6=>65)$. Additional half-open and open questions were integrated to enable specific answers. The amount of questionnaires and the return rate were recorded.

The survey was conducted at the end of the intervention and HCPs were given 19 days (3rd May - 22th May 2017) for feedback. The questionnaires and blank envelopes to maintain anonymity were handed out by the AHOI team. All participants were informed about the study's aims and data usage and security. Return of filled out questionnaires in closed envelopes was therefore understood as informed consent by participants.

The questionnaire included six question categories:

1. Acceptance (did HCPs identify with the AHOI project)

2. Evaluation of informational material (eg, videos and brochures)

3. Implementation (distribution of AHOI materials, training, support by materials, long-term assessment)

4. Hygiene and communication behavior of the HCPs (self-assessment of HCPs' own behavior recently) and assessment of colleagues (observed attention, support and happiness of colleagues)
5. Adherence (patients and visitors know hygiene standards and recognize and use them)

6. Empowerment through personnel (encouraging questions, informing about hygiene and AHOI)

\section{Data Processing and Data Analysis}

Collected data were entered in an active PDF format (Adobe Acrobat XI) by two independent research assistants and exported to SPSS. IBM SPSS Statistics 22 (Version 22.0; IBM Corporation, Armonk, NY, USA) was then used for data comparison, correction and statistical analysis. All presented percentages were rounded to the first place after the decimal point. Besides descriptive statistics, inferential methods such as correlation tests by Pearson's R and Spearman's Rho as well as Cramer's V, etc., were applied and reported when significant results were found.

\section{Results}

\section{Sample Description}

Questionnaires were given out to all 69 ward employees. Twenty-nine returns were registered and analyzed (42\%). Sex was not equally distributed, with a proportion of $77.3 \%(17 / 22)$ female and $22.7 \%$ (5/22) male respondents. Seven respondents did not answer this question. The HCPs had a mode age of 18-25 years (median age 26-35). Most employees $(18 / 29,62.1 \%)$ belonged to nursing personnel, 7 of 29 respondents were surgeons and 4 were others (Table 1). This corresponds to a surgeon-to-non-surgeon personnel ratio of one to three.

Because of the limited sample size, a subdivision of results by occupational groups is not reported.

\section{Acceptance}

With 24 of $29(82.8 \%)$ respondents, a majority of the respondents explicitly looked at the videos, information sheet and posters. The brochure was noticed and read by 20 of 29 HCPs $(69 \%)$. More than three-quarters of the respondents identified with the AHOI project (21/27, $77.7 \%$, unless otherwise indicated, this proportion always represents the proportion of positive responses; mean (MV): 7.6, standard deviation (SD): 2.3, scale 1-10 "not at all""very") (Figure 1A). Twenty of 25 respondents reported that their supervisor is committed to AHOI ("yes", 80\%).

\section{Evaluation of the Informational Material}

HCPs were asked to evaluate parts of the multimodal set of informational and motivational materials (Figure 1B). 
Table I Distribution of participating Health-Care Professionals' Sex, Age, and Occupational Group

\begin{tabular}{|c|c|c|}
\hline & Proportion & Frequency \\
\hline \multicolumn{3}{|l|}{ Sex } \\
\hline Female & $77.3 \%$ & $17 / 22$ \\
\hline Male & $22.7 \%$ & $5 / 22$ \\
\hline \multicolumn{3}{|l|}{ Age } \\
\hline $18-25$ years & $35.7 \%$ & $10 / 28$ \\
\hline $26-35$ years & $25 \%$ & $7 / 28$ \\
\hline $36-45$ years & $14.3 \%$ & $4 / 28$ \\
\hline $46-55$ years & $17.9 \%$ & $5 / 28$ \\
\hline $56-65$ years & $7.1 \%$ & $2 / 28$ \\
\hline \multicolumn{3}{|l|}{ Occupational group } \\
\hline Nursing personnel & $62.1 \%$ & $18 / 29$ \\
\hline Surgeons & $24.1 \%$ & $7 / 29$ \\
\hline Others* & $13.8 \%$ & $4 / 29$ \\
\hline
\end{tabular}

Notes: *Others, nursing apprentice, ward management assistant; To account for missing data, frequencies of every item are shown.

Reported answers are filtered by the items "watching videos" and "brochure" ("Which AHOI information source did you look at? - videos/brochure").

The overall impression of the brochure was rated as "good" by 13 of $20(65 \%)$ and as "medium" by 7 of 20 respondents $(35 \%)$.

The video Stay clean! was evaluated as "good" by 9 of $24(37.5 \%)$, "medium" by 11 of $24(45.8 \%)$ and as "bad" by 4 of $24(16.7 \%)$ respondents.

The video Mention It! was evaluated as "good" by 7 of $21(33.3 \%)$, "medium" by 9 of $21(42.8 \%)$ and as "bad" by 5 of $21(23.8 \%)$ respondents.

Almost all respondents thought that the patients and their relatives understood the AHOI posters $(26 / 28$, 92.9\%: "yes").

\section{Implementation}

A broad majority of the respondents did not perceive an additional workload by implementing the AHOI materials (18/28, 64.3\%, MV: 3, SD: 1.5, scale 1-6 "not at all""very") nor an increased time need for ICP measures since the implementation of AHOI (15/28, 53.6\%, MV: 3.4, SD: 1.5 , scale 1-6 "not at all"-“very").

A majority of the respondents felt supported thanks to the education of patients about important hygiene measures through the AHOI materials (14/20, 57.2\%, MV: 3.9, SD: 1.4 , scale 1-6 "not at all”-“very”).

\section{AHOI Training}

Nearly three of four respondents perceived the AHOI training as helpful $(14 / 20,70 \%, \mathrm{MV}: 7, \mathrm{SD}: 2.4$, scale 1-10 "not helpful"-"very helpful").

A small number of items of the sample correlated significantly at least at the $95 \%$ confidence level.

Assessment of the AHOI training correlated significantly with identification with the AHOI project (Pearson's R: 0.507, $\mathrm{p}=0.026$ ), and the respondents' assessment of the patients' reaction to hygiene feedback by the personnel (Pearson's R: 0.572, $\mathrm{p}=0.01$ ).

Likewise, assessment of the training also correlated with the perception that patients expressed concerns and problems towards HCPs. These two items correlated significantly (Spearman: $-.467, \mathrm{p}=0.039$ ) but negatively, due to converse coding of the patients' behavior item. The same is true for the respondents' attentiveness to the observance of hygienic rules by their colleagues (Spearman: $-.570, p=0.013$ ), the perceptions of relief felt by the respondents due to patients' correct hygiene behavior (Spearman: $-.480, \mathrm{p}=0.047$ ), and the respondents' assessment of their improved ability to deal with comments on their ICP behavior (Spearman: $-.687, \mathrm{p}=$ 0.002), as well as the respondents' perception of their feeling of being supported by the AHOI materials in educating patients about important ICP measures (Pearson's R: 0.630, $\mathrm{p}=0.004$ ).

\section{Long-Term Assessment}

Twenty of 25 respondents thought that a long-term employment of AHOI would improve the stress situation regarding hygiene activities on their ward (20/25, 80\%, MV: 2, SD: 0.8, scale 1-4 "fully agree"-“not agree", same scale for the following ten items).

\section{Hygiene and Communication Behavior of the HCPs HCPs' Self-Assessment}

A broad majority of 21 of 25 reported an increased vigilance in themselves towards ICP behavior of patients and their relatives $(84 \%, \mathrm{MV}: 1.9, \mathrm{SD}: 0.8)$ and to their own compliance with ICP rules (84\%, MV: 1.9, SD: 0.9).

Twenty-one of 23 respondents felt relieved in their workload if patients and their relatives showed adherence to $\mathrm{ICP}$ rules $(91.3 \%, \mathrm{MV}: 1.7, \mathrm{SD}: 0.8)$.

Six-teen of 24 HCPs felt supported if patients and their relatives paid attention to the respondents' ICP behavior (66.6\%, MV: 2.3, SD: 0.9). 


\section{A}

not at all

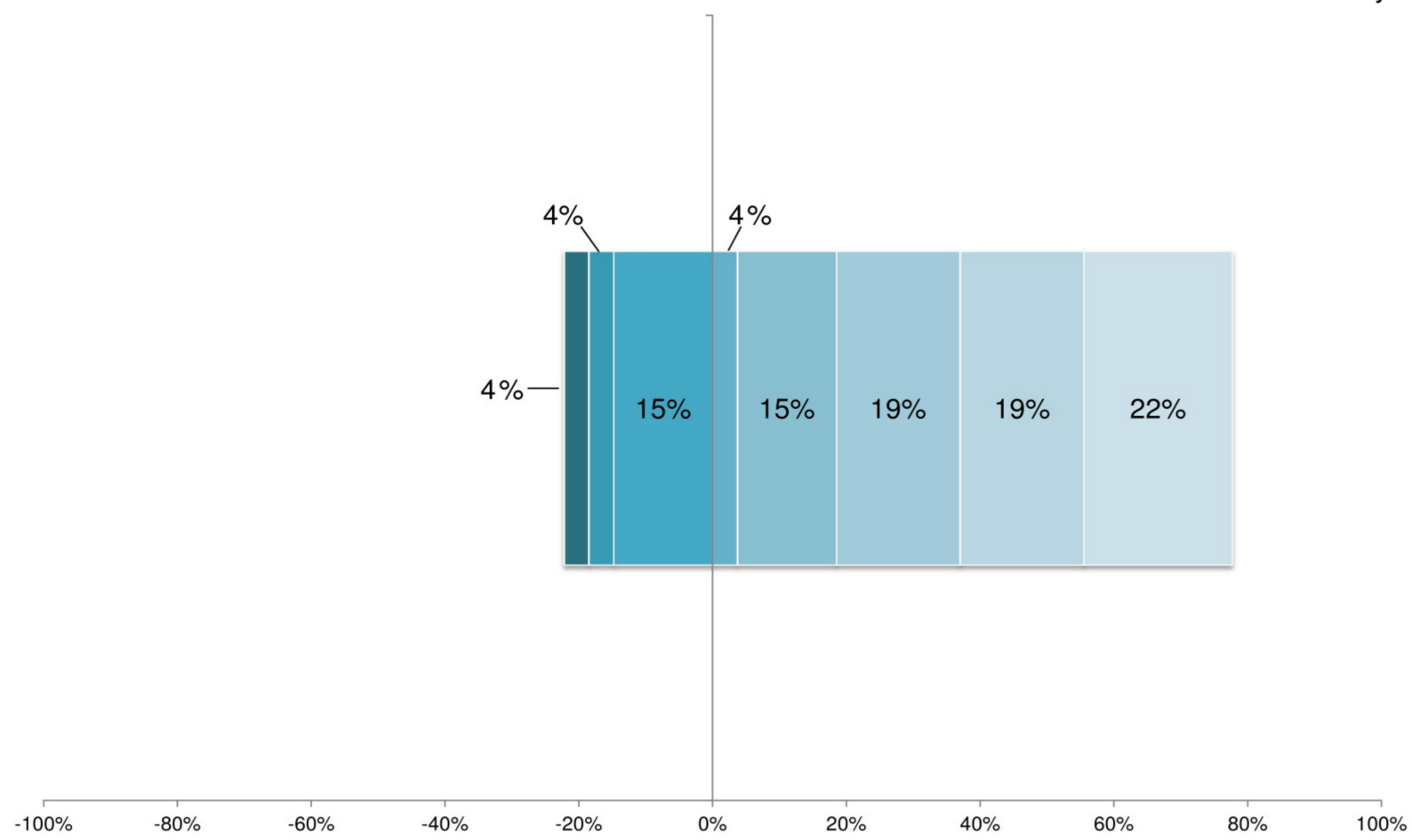

B

bad

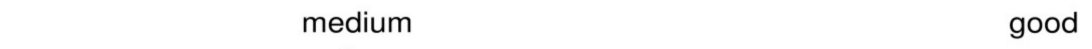

Video, Mention It!'

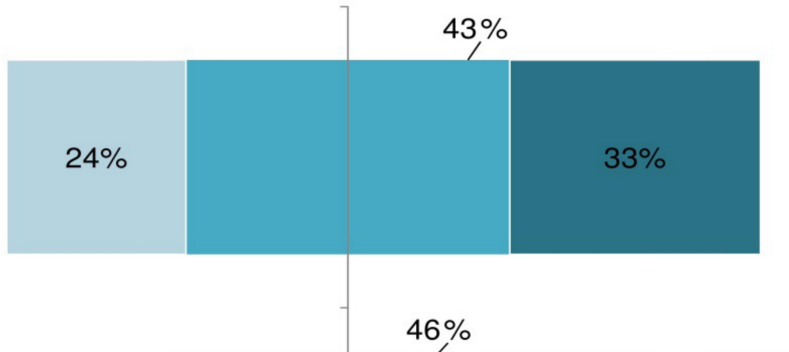

Video ,Stay Clean!‘
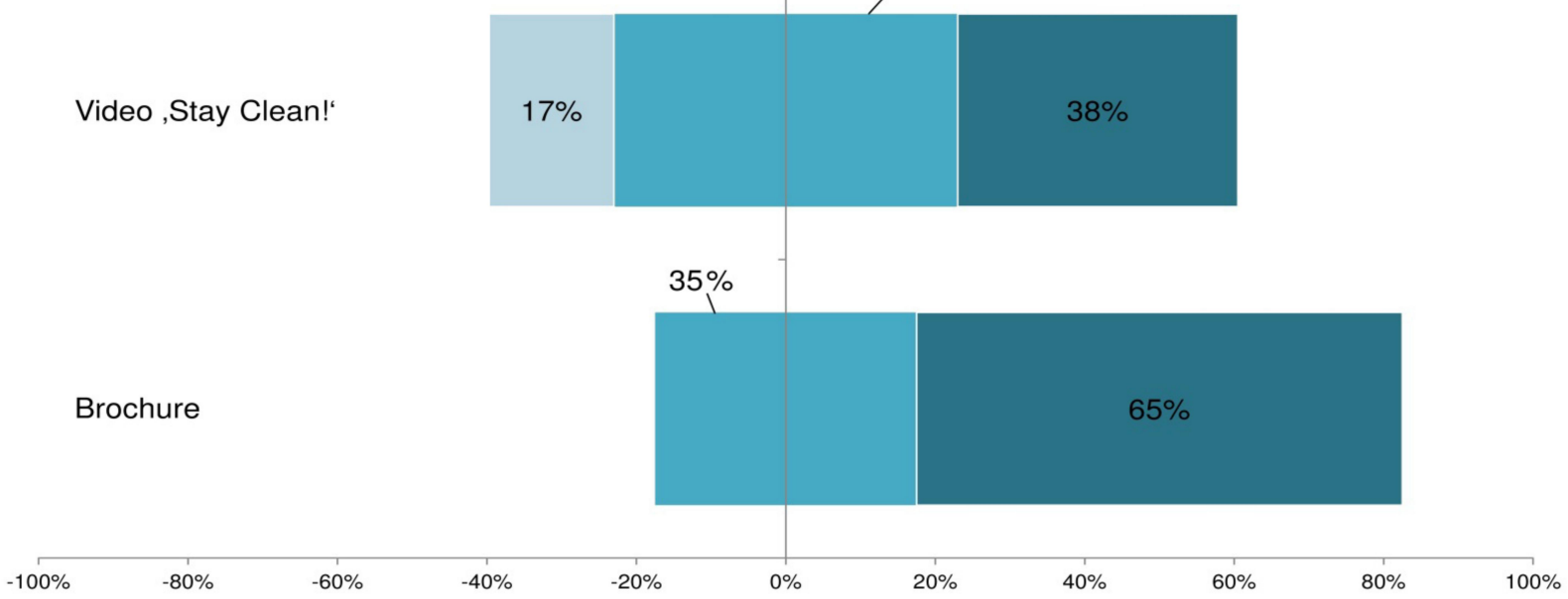

Figure I HCPs' identification with the AHOI-project (A) and Health Care Professionals' evaluation of AHOI materials (B).

Notes: Figure IA, Identification with AHOI, $n=27$. Scale: I="not at all" - I0="very"; Numeric answers to question: "How much can you identify with the AHOI content?"; Figure IB, Evaluation of AHOI materials. Video "Stay Clean!" $n=24$, Video "Mention It!" n= 2I, Brochure n= 20. Scale: "bad (emoticon)" - "middle (emoticon)" - "good (emoticon)"; Answer to questions:" How do you rate the animated film on the topic/the brochure?" 
Seventeen of 23 respondents reported that they are happier if patients and their relatives take responsibility in infection control (73.9\%, MV: 2, SD: 0.7).

\section{HCPs' Assessment of Colleagues}

A majority of HCPs reported that most of their colleagues showed an increased vigilance towards ICP behavior by patients and their relatives (21/24, 87.5\%, MV: 2, SD: 0.7$)$ and by other colleagues (17/23, 73.9\%, MV: 2.2, SD: 0.8 ). Nearly three-quarters of the respondents reported that most colleagues felt workload relief if patients and their relatives showed hygienic correct behavior (17/23, 73.9\%, MV: 2.2, SD: 0.7). A majority of the respondents reported that colleagues felt supported if patients and their relatives paid attention to the colleagues' hygienic behavior (18/23, 78.3\%, MV: 2.1, SD: 0.7).

\section{Happiness of Colleagues}

A greater number of respondents reported that their colleagues were happier if patients and their relatives take responsibility in infection control (21/24, 87.5\%, MV: 1.8 , SD: 0.7$)$.

\section{Adherence}

Almost nine out of ten respondents thought that the patients are integrated in infection prevention after implementation of the AHOI instruments (25/28, 89.2\%, MV: 7.5, SD: 1.6, scale 1-10 "not at all"-“very").

HCPs recognized an increase in hand disinfection use by patients according to the 5 moments of hand hygiene (21/26, 80.8\%, MV: 2.2, SD: 0.7 , scale 1-4 "fully agree""not agree"), also noticing improved general ICP behavior since AHOI implementation (22/29, 75.8\%, MV: 2, SD: 0.8 , scale 1-4 "Yes, the majority", "Yes, some", "Yes, but only a few", "No").

A majority of the respondents noticed that patients paid more attention to their ICP behavior in the bathroom (19/ 26, 73\%, MV: 2.3, SD: 0.6, scale 1-4 "fully agree"-"not agree"), especially when using the washbasin or the shower while AHOI was active (15/25, $60 \%$, MV: 2.4 , SD: 0.7 , scale 1-4 "fully agree"-"not agree").

A majority of HCPs estimated the reaction of patients as positive when confronted with their insufficient hygiene by HCPs during the AHOI implementation period (16/27, 59.2\%, MV: 6.4, SD: 2.2, scale 1-10 "negative"-“positive”).

\section{Empowerment Through Personnel}

With regard to empowerment, a majority of respondents reported that they encouraged the patients to pose questions
(18/27, 66.7\%, MV: 2.2, SD: 0.8, scale 1-4 "almost always""very rare", same scale for the following two items) and informed the patients about AHOI content (17/27, 65.4\%, MV: 2, SD: 1) and about correct ICP behavior (23/27, 85.2\%, MV: 2, SD: 0.7) (see Supplement 2).

More than three-quarters of the respondents noticed that patients and relatives paid more attention to the ICP behavior of HCPs (20/26, 76.9\%, MV: 2.1, SD: 0.7, scale 1-4 "fully agree"-"not agree").

\section{Discussion}

Hospital-associated infections and transmission, especially involving multi-resistant pathogens, are among the gravest concerns of patients in terms of hospitalization. ${ }^{30}$ Infection prevention is a fundamental task based on general hygienic rules in the hospital, especially since it is proven that patients are also possible transmitters of pathogens in clinical environments. ${ }^{6,31,32}$ As mentioned in the beginning, several studies on improvement of infection control and patient safety through better teaching and integration of the patient have been published previously. ${ }^{6-19}$ However, involving patients in ICP is an interesting and promising approach, but until today it is little known and attempted only rarely. Appropriate involvement of patients and relatives requires not only adherence by the affected persons, but also the acceptance of HCP. However, there is no evidence for patients' participation in improving HCPs' hand hygiene. ${ }^{7}$

The main goal of the study was to test the feasibility of the AHOI concept and its acceptance by HCPs. Implementation of AHOI was therefore carefully organized through a setup of teaching, supporting material and training. The introduction of AHOI materials was accompanied by a questionnaire-based survey to assess the preconditions, feasibility and possible initial effects of the intervention.

Using a structured questionnaire, we evaluated the acceptance of HCPs with the AHOI instruments and their perception of their own hygiene and communication behavior, as well as by patients and colleagues. The focus of this study was the role of HCPs, primarily their selfconception and personal development in the multimodal AHOI concept and their view on supporting materials, implementation, as well as teaching role for themselves (colleagues) and for the patients entrusted to them.

\section{Limitations}

Our report has several limitations. The number of respondents is limited due to the monocentric design, voluntariness, a regular high workload and the relatively short survey period 
and with $42 \%$ comparatively low. Low return rates might be a sign of a bias towards highly committed HCPs versus noninterested HCPs. Additionally, there is a general trend of decreasing response rates in sociological surveys because of increasing survey burden, technological innovations and societal changes. ${ }^{33}$ However, there are comparable studies with similar response rates. ${ }^{34,35}$ Because of this limitation, results by occupational group were not reported nor do the authors claim representativeness for the target population. Nevertheless, the authors are convinced that the results presented here show a first glimpse of possibilities and support the assumption that AHOI can promote adherence and empowerment of patients as well as acceptance of HCPs due to the similar results pointing in the same direction. Furthermore, because of the nature of a pilot study with the main goal to describe impressions and perceptions of healthcare professionals at a first implementation of AHOI, objective clinical parameters, eg, development wound infection rate, rate of surgical site infections or objective uses of hand disinfection were not collected, respectively, discussed in this paper. Future AHOI studies will be designed to show the value of AHOI instruments in objective parameters, such as hand rub consumption, lowered infection rates, or health economy factors with larger samples. ${ }^{17,32,36}$

\section{Interpretation}

The results demonstrate indications of increased acceptance and positive evaluation by health-care professionals in the sample. There are also results of an increased perception by the HCPs of improved adherence by their patients and a positive assessment of HCPs' encouragement to empower patients in the time of the study.

Supporting materials were explicitly registered, critically evaluated and recognized as helpful in education of patients, which is in line with related studies. ${ }^{37-42}$ Nonetheless, the $42 \%$ return rate of distributed questionnaires was relatively low. This may be due to workload combined with the short survey time. However, the implementation of AHOI was apparently welcome to the medical team. Identification with the AHOI project and the supervisor's commitment was reported as high by the respondents. The team leader's commitment or enhanced leadership is known as a very important point in patient safety. ${ }^{4-47}$ One possible reason for the increased identification or at least a coexisting key factor of the AHOI sample was the perception of the AHOI training as helpful.

The guided and supervised psychological training was the essential part of the implementation involving the
HCPs and was evaluated positively by a majority of the team. Essential skills were taught and enabled health-care professionals to interact with patients reasonably, respectfully, and appreciatively.

Within the sample, the efficiency of addressing problems, attentiveness toward observance of hygiene rules, dealing with comments and giving feedback correlated significantly with the AHOI training. The relation between training and an increase in professionalization were also found in other studies. ${ }^{7,48,49}$

AHOI shall improve subjective well-being of healthcare professionals in daily routine through stress reduction; better-educated patients may be recognized as more supportive and integrated in the process of inpatient care. Therefore, a minimum of workload increase was targeted by AHOI to support, not diminish patient safety. ${ }^{50-52}$ As a result, implementation was not perceived as an additional workload in the daily routine of patient-centered care; generally, greater time consumption due to hygienic activity was tolerated. Supporting and reminding materials such as posters, brochures and video presentations improved perceived patients' knowledge and finally patients' hygiene behavior, and conversely reduced the perceived workload of health-care professionals. Through implementation of the AHOI project, an environment was created for behavioral adjustment of the personnel themselves and in the observance of colleagues in a very positive way. Awareness of hygienic behavior of patients and professionals themselves was generally recognizable by the respondents. Professionals felt a relief in the case of correct behavior by patients. Feedback of patients was perceived as supportive, not offensive, which is another indicator for the acceptance of an egalitarian relationship between health-care professionals and patients. These perceptions were also confirmed by evaluating the opinion and the behavior of colleagues. The respondents reported that their colleagues pay more attention to hygiene compliance and feel positive about the support of patients and their relatives in hygiene behavior.

HCPs perceived an improvement in patient adherence, which probably served as a basis for these results. The respondents felt that the patients showed improved hygienic behavior since implementation of AHOI. An increase in self-reported hand hygiene compliance and a positive reaction to hygiene feedback by the personnel was noticed. This perceived increase again shows the importance of the double-edged approach where adherence by and empowerment of patients must meet with acceptance by the 
health-care professionals. Clearly, the personnel had the impression that the patients have a strong desire to improve and at the same time are open to communication about the subject of hygiene. This could be supported by help of the health-care professionals. The majority of respondents reported that they had informed the patients about the AHOI content and about correct hygiene as well as encouraged questions. That could indicate that the questioned personnel has accepted their new role and consequently created communication on equal footing with regard to communicating about hygiene. The topic is addressed and discussed with the patient, and thus omnipresent. Patients are referred directly to appropriate hygiene behaviors. Patients are also allowed to address hygiene issues, which is tolerated by the personnel and even desired in terms of patient safety. This could demonstrate the equality of the individuals involved and promotes a transparency and error-acknowledgement culture that adequately and effectively addresses future challenges of infection prevention.

\section{Generalisability}

With "AHOI - patient on board", a multimodal interdisciplinary concept was developed for the first time in Germany in order to systematically realize the demand of better teaching and integration of patients in hospital infection control and prevention. Although previous studies have shown a negative perception of patient empowerment by professionals, they also reported an awareness of the usefulness of patient hand hygiene..$^{24,53,54}$ Our results show that the implementation of a multimodal approach that addresses both groups of affected persons on different levels of communication, education and feedback, a positive perception of patient empowerment and integration in infection control by health-care professionals could be possible. This is a necessary condition for successful implementation of patient empowerment, where one of the greater challenges is properly handling patients' worries and fears. ${ }^{12,55-57}$ The AHOI concept seems to be feasible in daily hospital workflow and is a means of implementing national and international recommendations on hygienic behavior.

\section{Conclusions}

In view of the risks and challenges in modern patient safety, a fostered integration of patients and visitors should be an integral part of any solution. The presented results indicate that the three dimensions of adherence, empowerment and acceptance were fulfilled by the implemented AHOI strategy. The AHOI materials and perceived hygiene behavior that followed the implementation were favorably noticed and accepted by the HCPs.

In the eyes of the interviewed HCPs, the AHOI intervention led to increased patient adherence with correct hygienic behavior. Additionally, the patients demonstrated empowerment. Inferred cautiously, that could mean that the study shows that HCPs positively evaluate new strategies improving ICP. Further studies should provide harder read out parameters and objectively improved infection prevention.

\section{Abbreviations}

AHOI, Acronym standing for Activation, Help, Open communication and Infection prevention; ICP, infection control and prevention; WHO, World Health Organization; HCP, health care professional.

\section{Data Sharing Statement}

The dataset of the represented and analyzed data is available from the corresponding author on reasonable request.

\section{Ethics Approval and Informed Consent}

The study was accepted by the medical ethics commission of the Universitätsmedizin Greifswald (BB 087/16a). Every respondent got a blank envelope for the anonymous return of the questionnaire. An included information sheet invited the respondents to the voluntary and anonymous participation. The return of the questionnaires in closed envelopes was therefore viewed as informed consent. The study meets the guidelines outlined in the Declaration of Helsinki.

\section{Acknowledgments}

First of all, we want to thank the participating HCPs, the surgical wards, and their patients. Furthermore, we want to thank Mrs. Katja Schulz, Mrs. Stefanie Prellwitz, Mrs. Vivian Henck and Mrs. Janina Krafczyk-Korth for their preliminary and executive work for this study.

\section{Author Contributions}

All authors made a significant contribution to the work reported, whether that is in the conception, study design, execution, acquisition of data, analysis and interpretation, 
or in all these areas; took part in drafting, revising or critically reviewing the article; gave final approval of the version to be published; have agreed on the journal to which the article has been submitted; and agree to be accountable for all aspects of the work. Both authors contributed equally to the manuscript: Stephan Diedrich and Tillmann Görig.

\section{Funding}

This study was supported by public grants from the Federal Ministry of Health of the Federal Republic of Germany (grant number ZMVI 1 2516ZPK679).

\section{Disclosure}

Tillmann Görig reports grants from the Federal Ministry of Health of the Federal Republic of Germany, during the conduct of the study. Nils-Olaf Huebner reports grants from Federal Government of Germany, during the conduct of the study. The authors report no other potential conflicts of interest for this work.

\section{References}

1. WHO. WHO Guidelines on Hand Hygiene in Health Care - First Global Patient Safety Challenge Clean Care is Safer Care. Geneva: WHO Press; 2009.

2. Lewin SA, Skea ZC, Entwistle V, Zwarenstein M, Dick J. Interventions for providers to promote a patient-centred approach in clinical consultations. Cochrane Database Syst Rev. 2001;(4).

3. Dwamena F, Holmes-Rovner M, Gaulden CM, et al. Interventions for providers to promote a patient-centred approach in clinical consultations. Cochrane Database Syst Rev. 2012;12:CD003267.

4. Scholl I, Zill JM, Harter M, Dirmaier J. An integrative model of patient-centeredness - a systematic review and concept analysis. PLoS One. 2014;9(9):e107828. doi:10.1371/journal.pone.0107828

5. Fernandes Agreli H, Murphy M, Creedon S, et al. Patient involvement in the implementation of infection prevention and control guidelines and associated interventions: a scoping review. $B M J$ Open. 2019;9(3):e025824. doi:10.1136/bmjopen-2018-025824

6. Haverstick S, Goodrich C, Freeman R, James S, Kullar R, Ahrens M. Patients' hand washing and reducing hospital-acquired infection. Crit Care Nurse. 2017;37(3):e1-e8. doi:10.4037/ccn2017694

7. Stewardson A, Sax H, Gayet-Ageron A, et al. Enhanced performance feedback and patient participation to improve hand hygiene compliance of health-care workers in the setting of established multimodal promotion: a single-centre, cluster randomised controlled trial. Lancet Infect Dis. 2016;16(12):1345-1355. doi:10.1016/S14733099(16)30256-0

8. Davey P, Pagliari C, Hayes A. The patient's role in the spread and control of bacterial resistance to antibiotics. Clin Microbiol Infect. 2002;8:43-68. doi:10.1046/j.1469-0691.8.s.2.6.x

9. Gould D, Moralejo D, Drey N, Chudleigh JH, Taljaard M. Interventions to improve hand hygiene compliance in patient care (Review). Cochrane Database Syst Rev. 2017;(9).

10. Hibbard J, Greene J. What the evidence shows about patient activation: better health outcomes and care experiences; fewer data on costs. Health Aff. 2013;32(2):207-214. doi:10.1377/hlthaff. 2012.1061
11. Landers T, Abusalem S, Coty MB, Bingham J. Patient-centered hand hygiene: the next step in infection prevention. Am J Infect Control. 2012;40(4 Suppl 1):S11-17. doi:10.1016/j.ajic.2012.02.006

12. Longtin Y, Sax H, Allegranzi B, Hugonnet S, Pittet D. Patients' beliefs and perceptions of their participation to increase healthcare worker compliance with hand hygiene. Infect Control Hosp Epidemiol. 2009;30(9):830-839. doi:10.1086/599118

13. Wyer M, Jackson D, Iedema R, et al. Involving patients in understanding hospital infection control using visual methods. J Clin Nurs. 2015;24(11-12):1718-1729.

14. Schwappach D, Frank O, Koppenberg J, Müller B, Wasserfallen J-B. Patient's and healthcare workers' perceptions of a patient safety advisory. Int J Qual Health Care. 2011;23(6):713-720. doi:10.1093/ intqhe/mzr062

15. Schwappach D, Frank O, Buschmann U, Babst R. Effects on an educational patient safety campaign on patient's safety behaviours and adverse events. $J$ Eval Clin Pract. 2013;19:285-291. doi:10.1111/j.1365-2753.2012.01820.x

16. McGuckin M, Govednik J. Patient empowerment begins with knowledge: consumer perceptions and knowledge sources for hand hygiene compliance rates. Am J Infect Control. 2014;42:1106-1108. doi:10.1016/j.ajic.2014.06.007

17. Sunkesula V, Kundrapu S, Knighton S, Cadnum JL, Donskey CJ. A randomized trial to determine the impact of an educational patient hand-hygiene intervention on contamination of hospitalized patient's hands with healthcare-associated pathogens. Infect Control Hosp Epidemiol. 2017;38(5):595-597. doi:10.1017/ice.2016.323

18. Goerig T, Dittmann K, Kramer A, Diedrich S, Heidecke C-D, Huebner N-O. Infection control perception and behavior: a question of sex and gender? Results of the AHOI feasibility study. Infect Drug Resist. 2018;11:2511-2519. doi:10.2147/IDR.S178922

19. Gagné D, Bédard G, Maziade PJ. Systematic patient's hand disinfection: impact on meticillin-resistant Staphyloccocus aureus infection rates in a community hospital. J Hosp Infect. 2010;75:269-272. doi:10.1016/j.jhin.2010.02.028

20. Krafczyk-Korth J, Dittmann K, Heidecke C-D, Diedrich S, Kramer A, Hübner N-O. Aktive Einbeziehung von Patienten und Pflegebedürftigen in die Händedesinfektion. Epid Bull. 2017;18/ 19:166-168.

21. Huebner N-O, Krafczyk-Korth J. Projekt AHOI - Patienten in den Infektionsschutz einbinden. Heilberufe Spezial (Hygiene). 2016;17-18.

22. Goerig T, Huebner N-O. AHOI - Alle an Bord! - Infektionsschutz geht alle etwas an. Management \& Krankenhaus kompakt. 2018; (9):10-11.

23. Davis R, Parand A, Pinto A, Buetow S. Systematic review of the effectiveness of strategies to encourage patients to remind healthcare professionals about their hand hygiene. $J$ Hosp Infect. 2015;89:141-162. doi:10.1016/j.jhin.2014.11.010

24. Kim MK, Nam EY, Na SH, et al. Discrepancy in perceptions regarding patient participation in hand hygiene between patients and health care workers. Am J Infect Control. 2015;43:510-515. doi:10.1016/j. ajic. 2015.01 .018

25. Alzyood M, Jackson D, Brooke J, Aveyard H. An integrative review exploring the perceptions of patients and healthcare professionals towards patient involvement in promoting hand hygiene compliance in the hospital setting. $J$ Clin Nurs. 2018;27(7-8):1329-1345. doi:10.1111/jocn.14305

26. Butenko S, Lockwood C, McArthur A. Patient experiences of partnering with healthcare professionals for hand hygiene compliance: a systematic review. JBI Evidence Synthesis. 2017;15(6):1645-1670.

27. Goerig T, Dittmann K, Kramer A, Heidecke C-D, Diedrich S, Huebner N-O. Active involvement of patients and relatives improves subjective adherence to hygienic measures, especially self-reported hand hygiene: results of the AHOI pilot study. Antimicrob Resist Infect Control. 2019;8(1-9). 
28. Hutzschenreuter L, Hübner N-O, Dittmann K, Hassel A-V, Flessa S. Potential of innovations in hygiene management - a managerial perspective. Antimicrob Resist Infect Control. 2019;8:100. doi:10.1186/s13756-019-0555-x

29. von Elm E, Altman DG, Egger M, et al. The strengthening the reporting of observational studies in epidemiology (STROBE) statement: guidelines for reporting observational studies. PLoS Med. 2007;4(10):e296-e296. doi:10.1371/journal.pmed.0040296

30. Hamburg AK Studie: „Patientensicherheit - worauf es Patienten ankommt“. 2015. Available from: https://www.asklepios.com/presse/ presse-mitteilungen/konzernmeldungen/studie-patientensicherheitworauf-es-patienten-ankommt $\sim \mathrm{ref}=\mathrm{eb} 4 \mathrm{~b} 30 \mathrm{af}-4 \mathrm{bd} 6-4365-9 \mathrm{~b} 67$ 31 baebfb4962 . Accessed February 07, 2019.

31. Istenes N, Bingham J, Hazelett S, Fleming E, Kirk J. Patient's potential role in the transmission of health care-associated infections: prevalence of contamination with bacterial pathogens and patient attitudes toward hand hygiene. Am J Infect Control. 2013;41:793. doi:10.1016/j.ajic.2012.11.012

32. Cheng VCC, Tai JWM, Chau PH, et al. Successful control of emerging vancomycin-resistant enterococci by territory-wide implementation of directly observed hand hygiene in patients in Hong Kong. Am $J$ Infect Control. 2016;44:1168-1171.

33. Beullens K, Loosveldt G, Vandenplans C, Stoop I. Response rates in the European social survey: increasing, decreasing, or a matter of fieldwork efforts? Survey Methods: Insights from the Field. 2018:1-12.

34. Schwappach DL, Frank O, Davis RE. A vignette study to examine health care professionals' attitudes towards patient involvement in error prevention. J Eval Clin Pract. 2013;19(5):840-848.

35. Lastinger A, Gomez K, Manegold E, Khakoo R. Use of a patient empowerment tool for hand hygiene. Am J Infect Control. 2017;45 (8):824-829. doi:10.1016/j.ajic.2017.02.010

36. Eckmanns T, Schwab F, Bessert J, et al. Hand rub consumption and hand hygiene compliance are not indicators of pathogen transmission in intensive care units. J Hosp Infect. 2006;63(4):406-411. doi:10.1016/j.jhin.2006.03.015

37. Dela Cruz M, Tsark J, Chen J, Albright C, Braun K. Human papillomavirus (HPV) vaccination motivators, barriers, and brochure preferences among parents in multicultural Hawai'i: a qualitative study. J Cancer Educ. 2017;32(3):613-621. doi:10.1007/s13187-016-1009-2

38. Schoeps L, Tallberg A, Gunningberg L. Patients' knowledge of and participation in preventing pressure ulcers - an intervention study. Int Wound J. 2017;14:344-348. doi:10.1111/iwj.12606

39. Rumchev K, Brown H, Wheeler A, Pereira G. Behavioral interventions to reduce nickel exposure in a nickel processing plant. $J$ Occup Environ Hyg. 2017;14(10):823-830. doi:10.1080/15459624.2017. 1335402

40. Haisfield-Wolfe ME, Rund C. The development and pilot testing of a teaching booklet for oncology patients' self-assessment and perineal skin care. J Wound Ostomy Continence Nurs. 2002;29 (2):88-92.

41. Morris M, Friedemann Smith C, Boxell E, Wardle J, Simon A, Waller J. Quantitative evaluation of an information leaflet to increase prompt help-seeking for gynaecological cancer symptoms. $B M C$ Public Health. 2016;16(374). doi:10.1186/s12889-016-3032-y

42. Srigley JA, Furness CD, Gardam M. Interventions to improve patient hand hygiene: a systematic review. J Hosp Infect. 2016;94:23-29. doi:10.1016/j.jhin.2016.04.018
43. McFadden K, Stock G, Gowen CRI. Leadership, safety climate, and continuous quality improvement: impact on process quality and patient safety. Health Care Manage Rev. 2015;40(1):24-34. doi:10.1097/HMR.0000000000000006

44. Fischer S, Jones J, Verran J. Consensus achievement of leadership, organisational and individual factors that influence safety climate: implications for nursing management. J Nurs Manag. 2017;26 (1):50-58. doi:10.1111/jonm. 12519

45. Attree M, Newbold D. Risk, safety, and reliability. From cult to culture? J Nurs Manag. 2009;17:145-150. doi:10.1111/j.1365-2834.2009.01000.x

46. Huis A, Schoonhoven L, Grol R, Donders R, Hulscher M, Achterberg T. Impact of a team and leaders-directed strategy to improvise nurses' adherence to hand hygiene guidelines: a cluster randomised trial. Int J Nurs Stud. 2013;50:464-474. doi:10.1016/j.ijnurstu.2012.08.004

47. Huis A, Holleman G, Achterberg T, Grol R, Schoonhoven L, Hulscher M. Explaining the effects of two different strategies for promoting hand hygiene in hospital nurses: a process evaluation alongside a cluster randomised controlled trial. Implement Sci. 2013;8:41. doi:10.1186/1748-5908-8-41

48. Battistella G, Berto G, Bazzo S. Developing professional habits of hand hygiene in intensive care settings: an action-research intervention. Intensive Crit Care Nurs. 2017;38:53-59. doi:10.1016/ j.iccn.2016.08.003

49. Sansam S, Yamamoto E, Srun S, et al. Assessment of hand hygiene compliance after hand hygiene education among health care workers in Cambodia. Nagoya J Med Sci. 2016;78(2):151-162.

50. Sadule-Rios N, Aguilera G. Nurses' perceptions of reasons for persistent low rates in hand hygiene compliance. Intensive Crit Care Nurs. 2017;42:17-21. doi:10.1016/j.iccn.2017.02.005

51. Pittet D, Simon A, Hugonnet S, Pessoa-Silva CL, Sauvan V, Perneger TV. Hand hygiene among physicians: performance, beliefs, and perceptions. Ann Intern Med. 2004;141(1):1-8. doi:10.7326/ 0003-4819-141-1-200407060-00008

52. Lee A, Chalfine A, Daikos G, et al. Hand hygiene practices and adherence determinants in surgical wards across Europe and Israel: a multicenter observational study. Am J Infect Control. 2011;39 (6):517-520. doi:10.1016/j.ajic.2010.09.007

53. Sande-Meijide M, Lorenzo-Gonzalez M, Mori-Gamarra F, et al. Perceptions and attitudes of patients and health care workers toward patient empowerment in promoting hand hygiene. Am J Infect Control. 2019;47:45-50. doi:10.1016/j.ajic.2018.07.002

54. Burnett E. Perceptions, attitudes, and behavior towards patient hand hygiene. Am J Infect Control. 2009;37(8):638-642. doi:10.1016/j. ajic.2009.04.281

55. Seale H, Travaglia J, Chughtai A, Phillipson L, Novytska Y, Kaur R. 'I don't want to cause any trouble': the attitudes of hospital patients towards patient empowerment strategies to reduce healthcareacquired infections. J Infect Prev. 2015;16(4):167-173. doi:10.1177/ 1757177415588378

56. Seale H, Chughtai A, Kaur R, Phillipson L, Novytska Y, Travaglia J. Empowering patients in the hospital as a new approach to reducing the burden of health care-associated infections: the attitudes of hospital health care workers. Am J Infect Control. 2016;44(3):263-268. doi:10.1016/j.ajic.2015.10.003

57. Bell S, Roche S, Mueller A, et al. Speaking up about care concerns in the ICU: patient and family experiences, attitudes and perceived barriers. BMJ Qual Saf. 2018;27:928-936. doi:10.1136/bmjqs-2017-007525 


\section{Publish your work in this journal}

Infection and Drug Resistance is an international, peer-reviewed openaccess journal that focuses on the optimal treatment of infection (bacterial, fungal and viral) and the development and institution of preventive strategies to minimize the development and spread of resistance. The journal is specifically concerned with the epidemiology of antibiotic resistance and the mechanisms of resistance development and diffusion in both hospitals and the community. The manuscript management system is completely online and includes a very quick and fair peerreview system, which is all easy to use. Visit http://www.dovepress.com/ testimonials.php to read real quotes from published authors.

Submit your manuscript here: https://www.dovepress.com/infection-and-drug-resistance-journal 